\title{
Renal uptake of different radiolabelled peptides is mediated by megalin: SPECT and biodistribution studies in megalin-deficient mice
}

\author{
Erik Vegt • Marleen Melis • Annemarie Eek • \\ Monique de Visser • Maarten Brom • Wim J. G. Oyen • \\ Martin Gotthardt • Marion de Jong • Otto C. Boerman
}

Received: 5 August 2010 /Accepted: 15 November 2010/Published online: 18 December 2010

(C) The Author(s) 2010. This article is published with open access at Springerlink.com

\begin{abstract}
Purpose Radiolabelled peptides used for peptide receptor radionuclide therapy are excreted mainly via the kidneys and are partly reabsorbed and retained in the proximal tubular cells. The resulting high renal radiation dose can cause nephrotoxicity, limiting the maximum activity dose and the effectiveness of peptide receptor radionuclide therapy. The mechanisms of kidney reabsorption of these peptides are incompletely understood, but the scavenger receptor megalin has been shown to play a role in the reabsorption of ${ }^{111}$ In-octreotide. In this study, the role of megalin in the renal reabsorption of various relevant radiolabelled peptides was investigated.

Methods Groups of kidney-specific megalin-deficient mice and wild-type mice were injected with ${ }^{111}$ In-labelled somatostatin, exendin, neurotensin or minigastrin analogues. Single photon emission computed tomographic (SPECT) images of the kidneys were acquired and analysed
\end{abstract}

Erik Vegt and Marleen Melis contributed equally to this work.

E. Vegt - A. Eek - M. Brom - W. J. G. Oyen - M. Gotthardt •

O. C. Boerman

Department of Nuclear Medicine,

Radboud University Nijmegen Medical Centre,

Nijmegen, The Netherlands

M. Melis $\cdot$ M. de Visser $\cdot$ M. de Jong

Department of Nuclear Medicine, Erasmus MC,

Rotterdam, The Netherlands

\section{E. Vegt $(\bowtie)$}

Department of Nuclear Medicine, GROW School for Oncology \&

Developmental Biology, Maastricht University Medical Centre,

PO Box 5800, 6202 AZ Maastricht, The Netherlands

e-mail: ErikVegt@gmail.com quantitatively, or the animals were killed $3 \mathrm{~h}$ after injection and the activity concentration in the kidneys was measured. Results Megalin-deficient mice showed significantly lower uptake of all studied radiolabelled peptides in the kidneys, ranging from $22 \%$ ( ${ }^{111} \mathrm{In}$-octreotide) to $65 \%$ ( ${ }^{111}$ In-exendin) of uptake in wild-type kidneys. Quantitative analysis of renal uptake by SPECT and ex vivo measurements showed a very good correlation.

Conclusion Megalin is involved in the renal reabsorption of radiolabelled octreotide, octreotate, exendin, neurotensin and minigastrin. This knowledge may help in the design of strategies to reduce this reabsorption and the resulting nephrotoxicity in peptide receptor radionuclide therapy, enabling more effective therapy. Small-animal SPECT is an accurate tool, allowing in vivo quantification of renal uptake and serial measurements in individual mice.

Keywords Kidney $\cdot$ Megalin $\cdot$ Peptide receptor radionuclide therapy - Octreotide - Octreotate · Exendin · Neurotensin .

Minigastrin

\section{Introduction}

In peptide receptor radionuclide therapy (PRRT), radiolabelled peptide analogues are used to target tumours expressing particular receptors, such as the somatostatin receptor. Most radiolabelled peptides are predominantly cleared from the body via the kidneys. Rapid clearance of the radiolabelled peptides from the blood and low retention in the kidneys minimize the radiation dose to normal tissues. However, part of the filtered load of these small proteins and peptides is reabsorbed from the ultrafiltrate in the proximal tubules. Evidence suggests that, after glomerular filtration, 
proteins and peptides in the ultrafiltrate bind to endocytic receptors at the luminal surface of proximal tubular cells and are internalized. Subsequently, the compounds are transferred to the lysosomes, where they are proteolytically degraded into amino acids [1]. These are transported back into the bloodstream. However, residualizing radiolabels (e.g. N-terminal amino acid chelate conjugates or lysine chelate conjugates) are trapped in the tubular cell lysosomes and can deliver high radiation doses to the kidney tubules and glomeruli [2]. Nephrotoxicity is dose-limiting in PRRT with somatostatin analogues such as ${ }^{90}$ Y-DOTA-Tyr ${ }^{3}$-octreotide [3, 4].

The receptors involved in the tubular reabsorption of peptides have not yet been completely characterized, but for various nonradiolabelled peptides the involvement of megalin has been shown [5]. Megalin is a multiligand receptor belonging to the LDL receptor family. The receptor contains four large cysteine-rich ligand-binding domains and is a high-capacity pathway for the reabsorption of different structurally nonrelated peptides and proteins such as albumin, vitamin $\mathrm{D}$ binding protein, $\beta_{2}$-microglobulin and aprotinin $[5,6]$. De Jong et al. recently reported that the renal uptake of ${ }^{111}$ In-octreotide is significantly lower in kidney-specific megalin-deficient mice than in their wildtype counterparts, implicating the involvement of megalin in the renal reabsorption of radiolabelled somatostatin analogues [7]. Many other radiolabelled peptides that are being studied for their potential in tumour imaging and PRRT display renal retention severalfold higher than octreotide. Examples include exendin and minigastrin, targeting glucagon-like peptide-1 and cholecystokinin ${ }_{2}$ receptors, respectively $[8,9]$. It is unknown whether megalin is also involved in the renal uptake of these peptides.

In clinical PRRT with somatostatin analogues, the standard renoprotective regimen nowadays consists of coinfusion of basic amino acids, which are thought to interfere with the binding of somatostatin analogues to megalin or other endocytic receptors on the proximal tubular cells $[10,11]$. However, Gotthardt et al. have shown that the renal uptake of ${ }^{111} \mathrm{In}$-minigastrin is not reduced significantly by coinfusion of basic amino acids [9], suggesting that the reabsorption of this peptide is mediated by other receptors. Knowledge about the molecular mechanisms of proximal tubular reabsorption of different radiolabelled peptides is important to devise new methods to reduce their renal retention, for example by selecting or designing more efficient inhibitors of their renal reabsorption, or by structurally modifying the peptides to reduce their binding to renal receptors.

In this study, the role of megalin in the renal retention of $\left[{ }^{111} \mathrm{In}\right.$-DTPA-D-Phe $\left.{ }^{1}\right]$-octreotide ( ${ }^{111}$ In-octreotide), ${ }^{111}$ In-DTPA ${ }^{0}$-D-Phe ${ }^{1}$, Tyr $\left.^{3}\right]$-octreotate $\left({ }^{111}\right.$ In-octreotate), $\left[\right.$ Lys ${ }^{40}\left({ }^{111}\right.$ In-DTPA $\left.)\right]$-exendin-3 ( ${ }^{111}$ In-exendin $), \quad\left[{ }^{111} \mathrm{In}-\right.$ DOTA-Glu $\left.{ }^{1}\right]$-minigastrin $\left({ }^{111} \mathrm{In}\right.$-minigastrin) and $\left[{ }^{111} \mathrm{In}\right.$ -
DTPA $^{0}$ ]-neurotensin $\left({ }^{111}\right.$ In-neurotensin $)$ [6-13] was studied in mice. The renal uptake of the peptides was measured by single photon emission computed tomography (SPECT) imaging and by ex vivo measurements of kidney-specific megalin-deficient mice $\left(\right.$ megalin $^{\text {lox/lox}}$; $\left.\operatorname{apoE}^{\mathrm{Cre}}[12]\right)$ and wild-type mice. Since the level of renal uptake of radiopeptides may differ between female and male mice [13], both genders were imaged by SPECT.

\section{Materials and methods}

Animals

The megalin-deficient mice used were megalin ${ }^{\text {lox/lox }}$; apoE $\mathrm{E}^{\mathrm{Cre}}$ mice [12]. The principles of creating tissuespecific gene knockout models are described in detail elsewhere $[14,15]$. In brief, in megalin ${ }^{\text {lox/lox }}$; apoE $E^{\mathrm{Cre}}$ mice, expression of the enzyme Cre recombinase is controlled by the apolipoprotein $\mathrm{E}$ (apoE) promoter, and is thus produced only in tissues where the apoE gene is transcribed. In these tissues, Cre recombinase excises sequences from the genome that are flanked by two loxP sequences, in this case the megalin gene [14]. Animals were bred locally using males heterozygous for the apo $\mathrm{E}^{\mathrm{Cre}}$ gene. Offspring expressing the apo $\mathrm{E}^{\mathrm{Cre}}$ gene were identified by means of polymerase chain reaction (PCR) analysis as described below. Animals not expressing the apoE ${ }^{\text {Cre }}$ gene (megalin ${ }^{\text {lox/lox }}$ mice) were used as the wild type in the biodistribution studies. In the SPECT studies, C57B1/6 mice were used as the wild type.

\section{PCR analysis}

For PCR the primers CCCAAGAAGAGGAAGGTG (forward) and GCTGGCCCAAATGTTGCTG (reverse) were used. The reaction mixture consisted of approximately 50 ng mouse DNA in a total of $25 \mu$ colourless PCR buffer (Go Taq Flexi reaction buffer, Promega) with $5 \mathrm{mM} \mathrm{MgCl}{ }_{2}$ (Promega), $0.5 \mathrm{mM}$ deoxyribonucleotide triphosphate mix (dNTP, Promega), 12.5 pmol forward primer, 12.5 pmol reverse primer and 2.5 IU Taq polymerase (Promega). This mixture was heated for $4 \mathrm{~min}$ at $95^{\circ} \mathrm{C}$, followed by 32 cycles of $30 \mathrm{~s}$ at $95^{\circ} \mathrm{C}$, $30 \mathrm{~s}$ at $56^{\circ} \mathrm{C}$ and $30 \mathrm{~s}$ at $72^{\circ} \mathrm{C}$. After cycling, the temperature was maintained at $72^{\circ} \mathrm{C}$ for $10 \mathrm{~min}$ and subsequently lowered to $10^{\circ} \mathrm{C}$. The DNA formed was analysed by agarose gel electrophoresis.

\section{Radiolabelled compounds}

The following peptide derivatives were studied: [DTPA-D$\mathrm{Phe}^{1}$ ]-octreotide (Covidien) [16], [DTPA ${ }^{0}$-D-Phe ${ }^{1}, \mathrm{Tyr}^{3}$ ]- 
octreotate (Biosynthema) [17], [DTPA ${ }^{0}$ ]-neurotensin [6-13] (Biosynthema) [18], [Lys ${ }^{40}$-DTPA]-exendin-3 (exendin, Peptide Specialty Laboratories) [19], and [DOTA-Glu ${ }^{1}$ minigastrin (Peptide Specialty Laboratories) [20]. Relevant properties of the peptides are summarized in Table 1.

Peptides were labelled with ${ }^{111} \mathrm{InCl}_{3}(20 \mathrm{MBq} / \mathrm{nmol}$ for SPECT studies, $10-80 \mathrm{MBq} / \mathrm{nmol}$ for ex vivo biodistribution studies) as described previously [21]. Labelling efficiency and radiochemical purity of the labelled peptides were determined by silica gel instant thin-layer chromatography and reverse-phase high-performance liquid chromatography. Radiochemical purity was $>95 \%$ for all compounds.

\section{SPECT studies}

Megalin-deficient and wild-type mice (male and female, four to six per group) received an intravenous injection of $40 \mathrm{MBq}(0.2 \mathrm{ml}, 2 \mathrm{nmol}){ }^{111}$ In-octreotide. The exact injected activity was determined by measuring the syringe in a dose calibrator before and after injection. A 24-min SPECT scan of the kidney region was acquired 3 and $24 \mathrm{~h}$ after injection with a four-headed helical NanoSPECT/CT system (Bioscan) using Nucline software (v 2.01, Mediso). Multipinhole mouse collimators with nine pinholes $(1.4 \mathrm{~mm}$ diameter) per head were used, with a matrix of $256 \times 256$ and 24 projections ( 2 min per projection). During the scan the animals were anaesthetized with isoflurane $/ \mathrm{O}_{2}$ and body temperature was maintained. This procedure was repeated in the same mice with ${ }^{111}$ In-octreotate, ${ }^{111}$ In-exendin, ${ }^{111} \mathrm{In}$ neurotensin and ${ }^{111}$ In-minigastrin consecutively at intervals of at least 3 weeks. Some of the animals developed signs of kidney damage at the end of this series of experiments, probably caused by the relatively high renal uptake of ${ }^{111} \mathrm{In}$ exendin, resulting in a high radiation dose to the kidneys [22]. Therefore, the ${ }^{111}$ In-exendin, ${ }^{111}$ In-neurotensin and ${ }^{111}$ In-minigastrin data were discarded and an extra experiment with these peptides was carried out in a new set of animals. To reduce the risk of kidney damage, the injected activity of ${ }^{111}$ In-minigastrin and ${ }^{111} \mathrm{In}$-exendin was reduced to $10 \mathrm{MBq}$, while the peptide dose was kept constant at 2 nmol. In this second series, SPECT scans were acquired only $3 \mathrm{~h}$ after injection.

SPECT scans were reconstructed iteratively using InVivoScope software (v 1.32, Bioscan) with medium noise reduction, a voxel size of $0.3 \mathrm{~mm}^{3}$ and standard reconstruction settings. The amount of radioactivity in a volume of interest drawn around the kidneys was quantified and expressed as percent of injected dose per gram tissue $(\% \mathrm{ID} / \mathrm{g})$. To achieve accurate quantification, the camera was calibrated by scanning a $20-\mathrm{ml}$ polypropylene tube mouse phantom filled with a known amount of ${ }^{111} \mathrm{In}$ activity.
After the final SPECT scan, the animals were killed and the biodistribution of ${ }^{111}$ In-minigastrin and ${ }^{111}$ In-exendin was determined as described in the next section to confirm the accuracy of the SPECT measurements.

Ex vivo biodistribution studies

Animals (four to six per group) received an intravenous injection of $0.4 \mathrm{MBq}(0.2 \mathrm{ml}, 5-40 \mathrm{pmol}){ }^{111}$ In-octreotide, ${ }^{111}$ In-exendin, ${ }^{111}$ In-neurotensin or ${ }^{111}$ In-minigastrin. For

${ }^{111}$ In-octreotide the experiment was performed with male and female mice; for the other peptides only female mice were used. The animals were killed $3 \mathrm{~h}$ after injection, and organs were dissected. The biodistribution of the ${ }^{111} \mathrm{In}$ labelled peptides was determined by weighing the organs and measuring the radioactivity in a gamma counter. Measured activity was expressed as $\% \mathrm{ID} / \mathrm{g}$. The right kidney of each animal was cut in half. One half was snapfrozen in liquid nitrogen and processed for cryosectioning, the other half was processed for paraffin sectioning. Frozen $10-\mu \mathrm{m}$ sections were mounted on glass slides for autoradiography. A phosphor imaging screen was exposed to the sections for 2 days and scanned using a BAS 1800-II phosphor imager (Fujifilm).

\section{Immunohistochemistry}

Frozen 5 - $\mu \mathrm{m}$ kidney sections were fixed in $4 \%$ formalin for $10 \mathrm{~min}$. After rinsing with $0.05 \%$ polysorbate 80 in PBS, the sections were incubated with goat anti-rat megalin polyclonal antibody (SC-16478, Santa Cruz) $10 \mu \mathrm{g} / \mathrm{ml}$ in PBS with $5 \%$ BSA for $1 \mathrm{~h}$ at room temperature, followed by incubation with horseradish peroxidase-conjugated donkey anti-goat $\operatorname{IgG}, \mathrm{F}\left(\mathrm{ab}^{\prime}\right)_{2}$ (SC-3851, Santa Cruz) 1/ 100 for $30 \mathrm{~min}$ at room temperature. Peroxidase activity was visualized with diaminobenzidine (Powervision) and nuclei were counterstained using haematoxylin. Slides were dehydrated with ethanol and xylene and embedded in slide mounting fluid (Permount), after which they were studied microscopically. Megalin expression was scored visually by an independent, blinded observer on an arbitrary scale of 0 (negative) to 4 (all tubules positive).

Statistical analysis

Data are presented as mean values \pm standard deviation. Renal uptake values were compared using Student's $t$-test. For the SPECT studies of ${ }^{111}$ In-minigastrin and ${ }^{111} \mathrm{In}$ exendin (after which the mice were killed), the correlation between renal uptake measured on the SPECT images and uptake in the same mice measured ex vivo was determined. Spearman's rank correlation coefficient was calculated with SPSS 16.0 (SPSS). 
Table 1 Characteristics of studied peptide analogues

\begin{tabular}{|c|c|c|c|c|}
\hline Peptide analogue & Target receptor & Molecular weight $(\mathrm{kDa})$ & Number of amino acid residues (positive/negative) & Charge at $\mathrm{pH} 7$ \\
\hline${ }^{111}$ In-Octreotide & Somatostatin receptor $_{2}$ & 1.5 & $8\left(1+/ 0^{-}\right)$ & +1 \\
\hline${ }^{111}$ In-Octreotate & Somatostatin receptor ${ }_{2}$ & 1.5 & $8(1+/ 0-)$ & +1 \\
\hline${ }^{111}$ In-Exendin & Glucagon-like peptide-1 & 4.8 & $39\left(4+/ 6^{-}\right)$ & -2 \\
\hline${ }^{111}$ In-Minigastrin & Cholecystokinin $_{2}$ and gastrin & 2.1 & $13(0+/ 7-)$ & -7 \\
\hline${ }^{111}$ In-Neurotensin & Neurotensin & 1.3 & $8(1+/ 0-)$ & +1 \\
\hline
\end{tabular}

\section{Results}

Immunohistochemistry

Immunostaining revealed lower expression of megalin in the kidney cortex of the megalin-deficient mice as compared to the wild-type mice. The expression of megalin in the megalin-deficient kidneys varied considerably, ranging from almost absent (score 0 ) to moderate expression (score 2). Examples are shown in Fig. 1.

\section{SPECT measurement of renal peptide uptake}

As shown in Fig. 2, the kidneys were visualized very well on the SPECT scans acquired at $3 \mathrm{~h}$ after injection. The images indicated that the radioactivity mainly accumulated in the renal cortex.

The measured renal uptake values of the ${ }^{111}$ In-labelled peptides as derived from the SPECT images at $3 \mathrm{~h}$ after injection and the ratios of uptake between megalin-deficient mice and wild-type mice are presented in Table 2. The data are summarized together with the ex vivo biodistribution data in Fig. 3. ${ }^{111}$ In-exendin expressed the highest renal uptake: $371 \pm 35 \% \mathrm{ID} / \mathrm{g}$ in female wild-type mice. The peptide with the lowest renal uptake $(15 \pm 2.7 \% \mathrm{ID} / \mathrm{g}$ in female wild-type mice) was ${ }^{111}$ In-neurotensin. In the SPECT studies, the renal retention of all ${ }^{111}$ In-labelled peptides was significantly lower in megalin-deficient mice than in wild-type mice, both in males and females. The effect was most prominent for ${ }^{111} \mathrm{In}$-neurotensin, for which the renal uptake in female megalin-deficient mice was only $23 \%$ of the uptake in wild-type mice $(p<0.0001)$. The least effect was observed with ${ }^{111}$ In-exendin, for which the uptake in female megalin-deficient mice was $62 \%$ of the uptake in wild-type mice $(p=0.003)$.

The data measured $24 \mathrm{~h}$ after injection are presented in Table 2. The renal uptake of the studied radiolabelled peptides remained significantly lower in the megalindeficient mice, both in females and in males. Overall, the uptake of ${ }^{111}$ In-octreotide and ${ }^{111}$ In-octreotate was significantly lower in male mice than in female mice: the retention of ${ }^{111}$ In-octreotide in males was too low to delineate the kidneys and the uptake of ${ }^{111}$ In-octreotate was more than threefold lower in males than in females. For ${ }^{111}$ In-exendin, no difference between the genders was observed.

\section{Ex vivo measurement of renal uptake}

The renal uptake of the ${ }^{111}$ In-labelled peptides measured ex vivo in megalin-deficient and wild-type mice is presented in Table 3 and summarized in Fig. 3. The renal uptake of ${ }^{111}$ Inoctreotide, ${ }^{111}$ In-octreotate, ${ }^{111}$ In-minigastrin and ${ }^{111}$ In-neurotensin was significantly lower in the megalin-deficient mice than in the wild-type mice. The effect was most prominent for ${ }^{111}$ In-octreotide, for which the renal uptake in female megalin-deficient mice was only $22 \%$ of the uptake in wild-type mice $(p=0.0007)$. For ${ }^{111}$ In-exendin, no significant difference in renal uptake between the two groups was observed when a peptide dose of 5 pmol was used. However, when a higher peptide dose of 2 nmol was
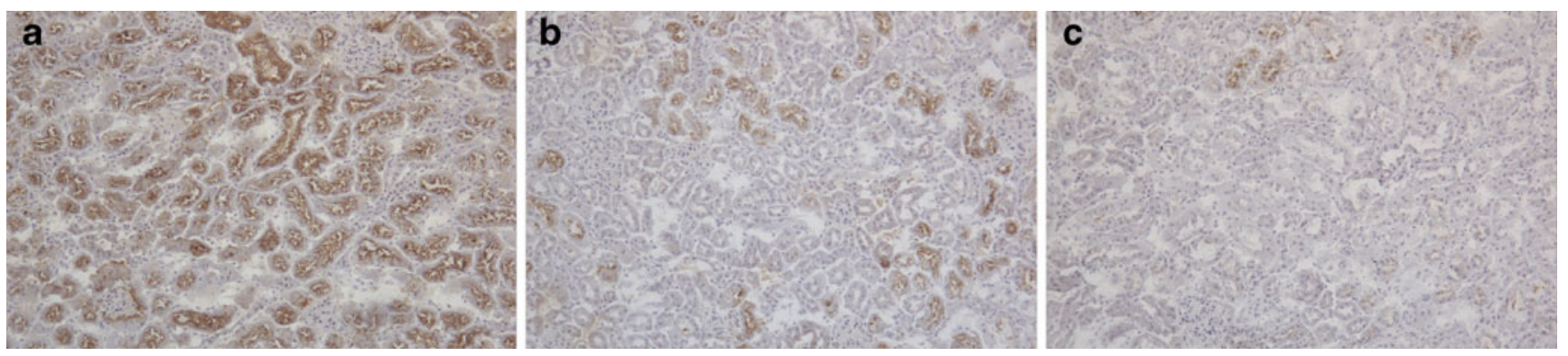

Fig. 1 Anti-megalin immunostaining of kidney cortex from a wild-type mouse (a) and from two megalin-deficient mice exhibiting relatively high (b) and relatively low (c) residual expression of megalin 
Fig. 2 SPECT images of the kidneys of wild-type (a) and megalin-deficient (b) mice $3 \mathrm{~h}$ after injection of ${ }^{111}$ In-minigastrin (left maximum intensity projections, right coronal slices)
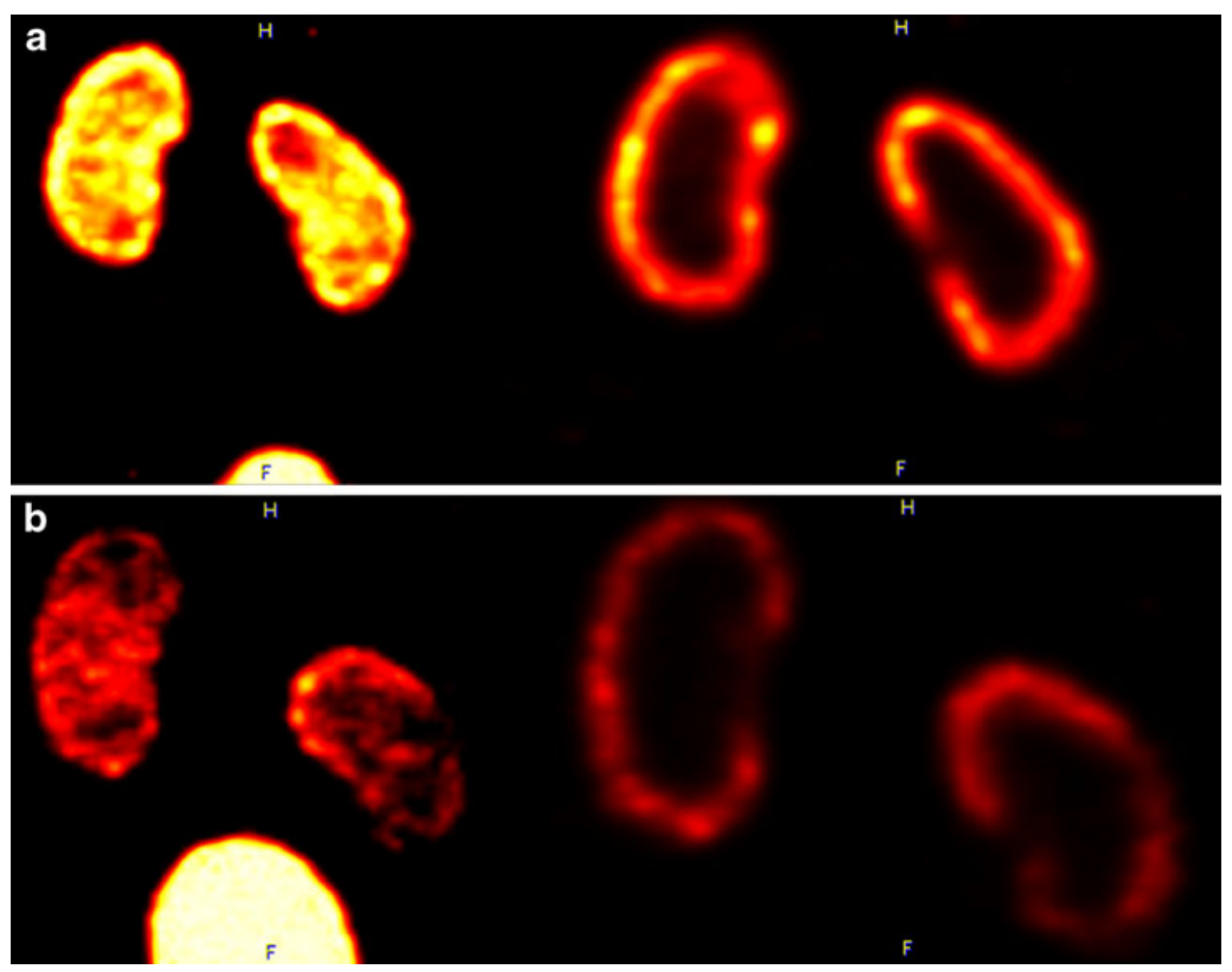

administered for SPECT imaging, a significant difference was measured, both on SPECT and ex vivo (see Table 3).

Autoradiography of the kidneys revealed a patchy distribution of the ${ }^{111}$ In-labelled peptides, mainly in the renal cortex (Fig. 4), and confirmed lower uptake in the kidneys of the megalin-deficient mice.
Biodistribution of ${ }^{111}$ In-labelled octreotide, octreotate, neurotensin and minigastrin in organs other than the kidneys did not differ significantly between the wild-type and megalin-deficient mice (data not shown). For the high dose of ${ }^{111}$ In-exendin (2 nmol), lung uptake in the wild-type animals was significantly higher than in the megalin-

Table 2 Renal uptake of radiolabelled peptides on SPECT in wild-type and megalin-deficient mice

\begin{tabular}{|c|c|c|c|c|}
\hline Peptide & Gender & Wild-type $(\% \mathrm{ID} / \mathrm{g} \pm \mathrm{SD})$ & Megalin-deficient $(\% \mathrm{ID} / \mathrm{g} \pm \mathrm{SD})$ & Ratio megalin-deficient/wild-type \\
\hline \multicolumn{5}{|l|}{$3 \mathrm{~h}$ after injection } \\
\hline \multirow[t]{2}{*}{${ }^{111}$ In-Octreotide } & Female & $17 \pm 2.4$ & $8.5 \pm 2.6$ & $49 \%(p=0.001)$ \\
\hline & Male & $22 \pm 5.6$ & $5.7 \pm 2.0$ & $26 \%(p=0.0003)$ \\
\hline \multirow[t]{2}{*}{${ }^{111}$ In-Octreotate } & Female & $16 \pm 4.6$ & $7.6 \pm 2.4$ & $46 \%(p=0.007)$ \\
\hline & Male & $16 \pm 2.8$ & $5.9 \pm 1.9$ & $36 \%(p=0.0001)$ \\
\hline \multirow[t]{2}{*}{${ }^{111}$ In-Exendin } & Female & $371 \pm 35$ & $230 \pm 58$ & $62 \%(p=0.003)$ \\
\hline & Male & $328 \pm 51$ & $171 \pm 34$ & $52 \%(p=0.001)$ \\
\hline \multirow[t]{2}{*}{${ }^{111}$ In-Minigastrin } & Female & $89 \pm 10$ & $33 \pm 8.9$ & $37 \%(p<0.0001)$ \\
\hline & Male & $104 \pm 13$ & $52 \pm 14$ & $49 \%(p=0.0003)$ \\
\hline \multirow[t]{2}{*}{${ }^{111}$ In-Neurotensin } & Female & $15 \pm 2.7$ & $3.6 \pm 1.18$ & $23 \%(p<0.0001)$ \\
\hline & Male & $18 \pm 9.0$ & $4.6 \pm 1.1$ & $25 \%(p=0.02)$ \\
\hline \multicolumn{5}{|l|}{$24 \mathrm{~h}$ after injection } \\
\hline \multirow[t]{2}{*}{${ }^{111}$ In-Octreotide } & Female & $2.2 \pm 0.25$ & $1.4 \pm 0.47$ & $64 \%(p=0.0001)$ \\
\hline & Male & Not measurable & Not measurable & - \\
\hline \multirow[t]{2}{*}{${ }^{111}$ In-Octreotate } & Female & $5.3 \pm 0.97$ & $2.5 \pm 0.71$ & $47 \%(p=0.001)$ \\
\hline & Male & $1.6 \pm 0.37$ & $0.44 \pm 0.20$ & $28 \%(p=0.0003)$ \\
\hline \multirow[t]{2}{*}{${ }^{111}$ In-Exendin } & Female & $148 \pm 11$ & $82 \pm 24$ & $55 \%(p=0.0005)$ \\
\hline & Male & $142 \pm 10$ & $69 \pm 19$ & $49 \%(p=0.0001)$ \\
\hline
\end{tabular}


Fig. 3 Renal uptake of ${ }^{111}$ Inlabelled peptides in wild-type and megalin-deficient mice, as measured by ex vivo biodistribution studies and SPECT $3 \mathrm{~h}$ after injection. Results are presented as mean $\% \mathrm{ID} / \mathrm{g}$; error bars indicate standard error of the mean. ${ }^{*} p<0.05$

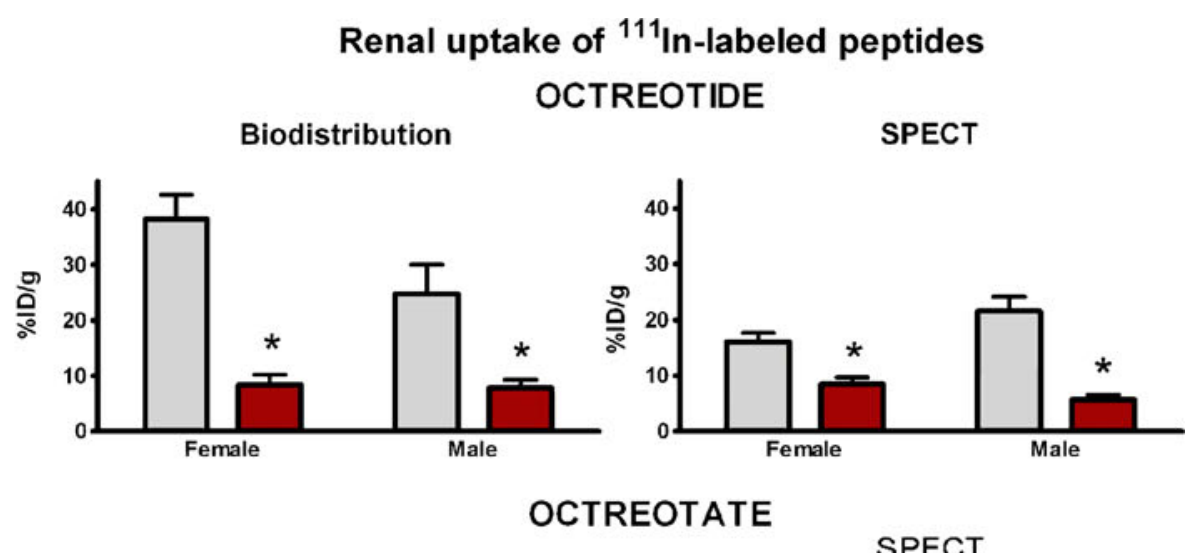

I I Wild type

$\square$ Megalin-deficient
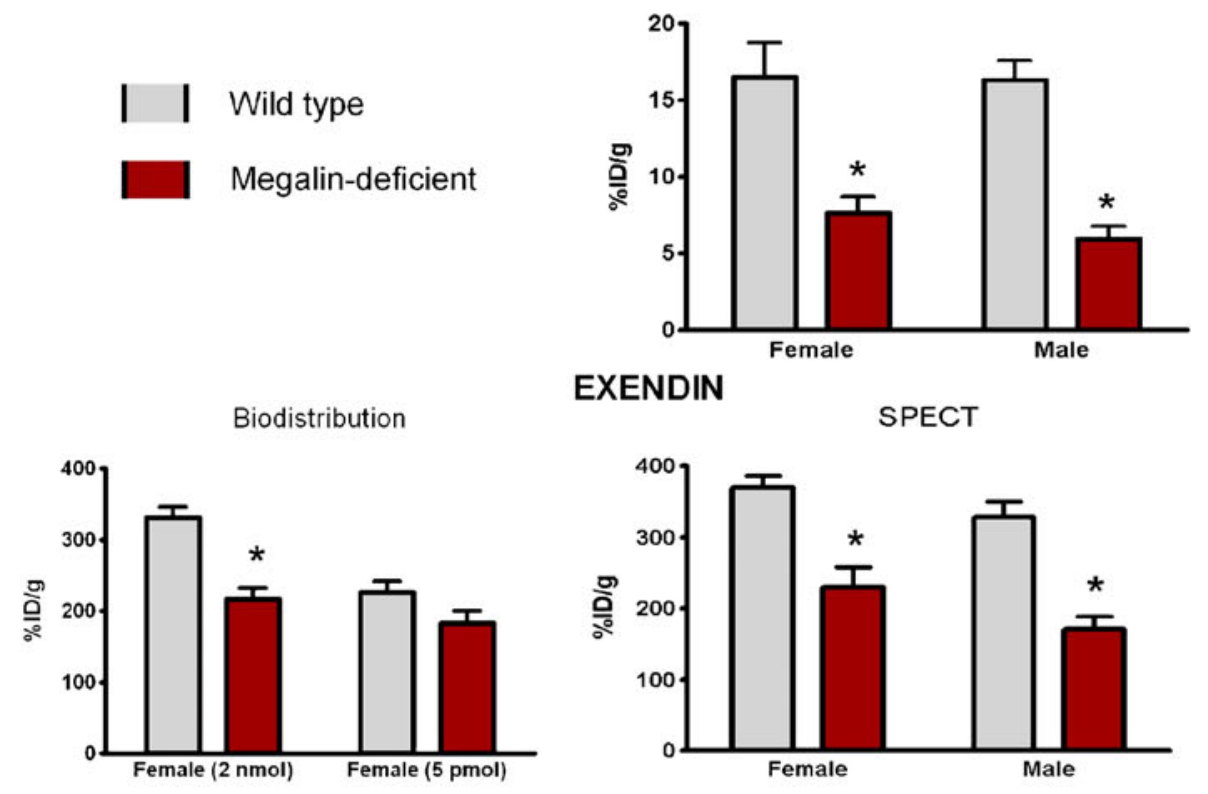

Biodistribution
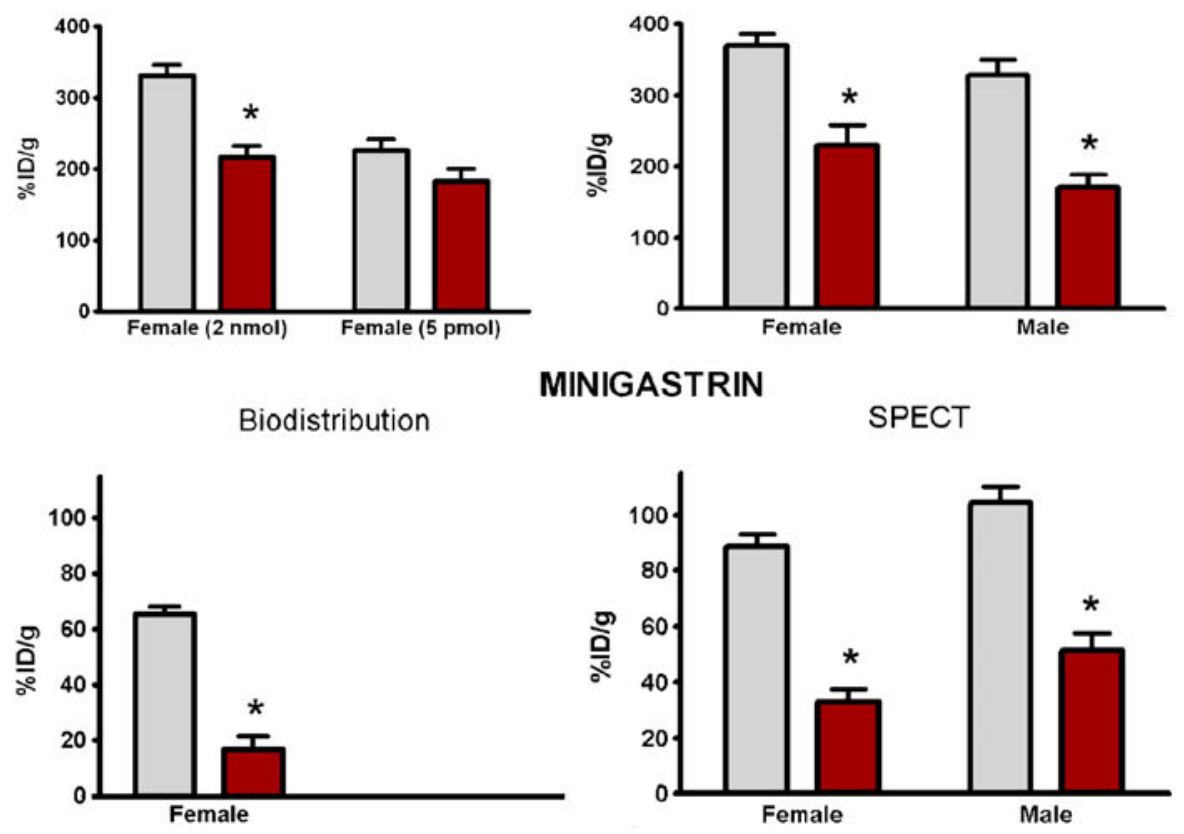

Biodistribution

NEUROTENSIN
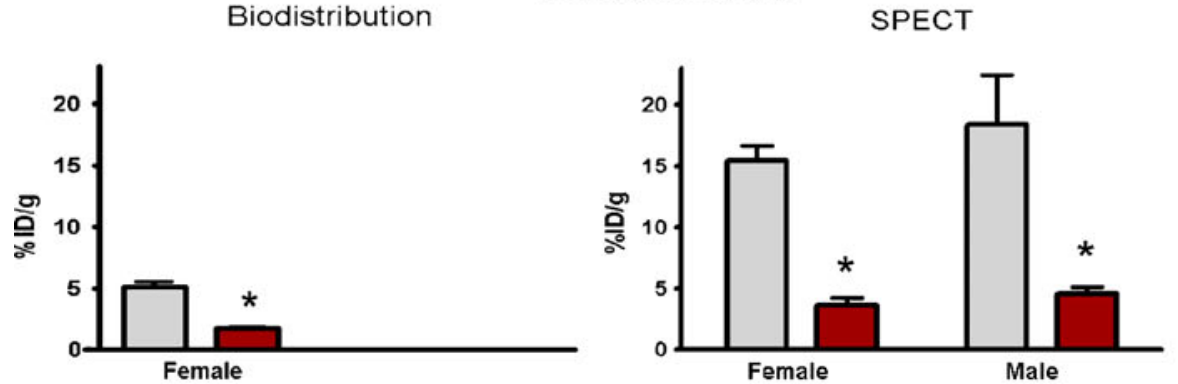
Table 3 Renal uptake of radiolabelled peptides measured ex vivo $3 \mathrm{~h}$ after injection in wild-type and megalin-deficient mice

\begin{tabular}{lllll}
\hline Peptide & Gender & Wild-type $(\% \mathrm{ID} / \mathrm{g} \pm \mathrm{SD})$ & Megalin-deficient $(\% \mathrm{ID} / \mathrm{g} \pm \mathrm{SD})$ & Ratio megalin-deficient/wild-type \\
\hline${ }^{111}$ In-Octreotide & Female & $38 \pm 9.8$ & $8.4 \pm 3.5$ & $22 \%(p=0.0007)$ \\
& Male & $25 \pm 12$ & $7.9 \pm 2.7$ & $32 \%(p=0.03)$ \\
${ }^{111}$ In-Exendin $2 \mathrm{nmol}^{\mathrm{a}}$ & Female & $331 \pm 33$ & $215 \pm 34$ & $65 \%(p=0.001)$ \\
${ }^{111}$ In-Exendin $5 \mathrm{pmol}^{\mathrm{a}}$ & Female & $225 \pm 35$ & $183 \pm 39$ & $81 \%(\mathrm{~ns})$ \\
${ }^{111}$ In-Minigastrin & Female & $66 \pm 5.9$ & $17 \pm 9.1$ & $26 \%(p<0.0001)$ \\
${ }^{111}$ In-Neurotensin & Female & $5.1 \pm 0.94$ & $1.7 \pm 0.18$ & $34 \%(p<0.0001)$ \\
\hline
\end{tabular}

ns not significant.

a ${ }^{111}$ In-Exendin was measured ex vivo in two experiments: after the final SPECT scan using 2 nmol peptide, and in a separate biodistribution experiment using 5 pmol peptide.

deficient mice $(1.2 \pm 0.18 \% \mathrm{ID} / \mathrm{g}$ vs. $0.23 \pm 0.037 \% \mathrm{ID} / \mathrm{g}$ in females, and $0.98 \pm 0.039 \% \mathrm{ID} / \mathrm{g}$ vs. $0.26 \pm 0.034 \% \mathrm{ID} / \mathrm{g}$ in males; both $p<0.0001)$. However, in the animals that received the low dose of $5 \mathrm{pmol}{ }^{111}$ In-exendin, no difference in lung uptake was observed: in both the wild-type and the megalin-deficient mice, lung uptake was $11 \% \mathrm{ID} / \mathrm{g}$, much higher than in the animals that received 2 nmol of peptide.

\section{Correlation between biodistribution and SPECT}

The correlation between renal uptake values measured by biodistribution and SPECT was very good, as depicted in Fig. 5. Spearman's rank correlation coefficient was 0.924 $\left(r^{2}=0.85, p<0.0005\right)$.

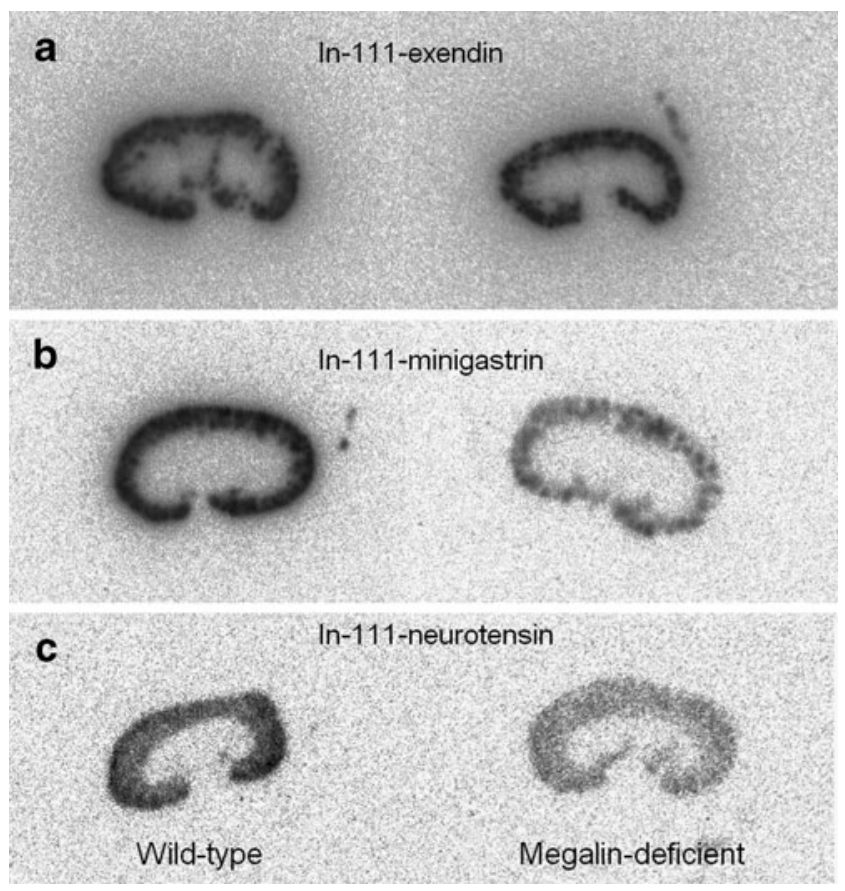

Fig. 4 Autoradiography of kidneys of wild-type and megalindeficient mice that received ${ }^{111}$ In-exendin (a), ${ }^{111}$ In-minigastrin (b) or ${ }^{111}$ In-neurotensin (c)

\section{Discussion}

In the present study we showed that the multiligand receptor megalin is involved in the proximal tubular reabsorption of ${ }^{111} \mathrm{In}$-octreotate, ${ }^{111} \mathrm{In}$-minigastrin, ${ }^{111} \mathrm{In}$ neurotensin and probably of ${ }^{111}$ In-exendin, and we confirmed megalin's role in the reabsorption of ${ }^{111} \mathrm{In}$ octreotide: the renal uptake of these peptides in megalindeficient mice was reduced to $23-65 \%$ of the uptake in wild-type mice. The remaining renal uptake of the radiolabelled peptides in the megalin-deficient mice may have been due to residual megalin expression. The knock-out of megalin expression in the kidneys of these megalin ${ }^{\text {lox/lox }}$; apoE $\mathrm{E}^{\mathrm{Cre}}$ mice occurs in a mosaic pattern, with a considerable percentage of tubular cells expressing normal levels of megalin, presumably caused by insufficient

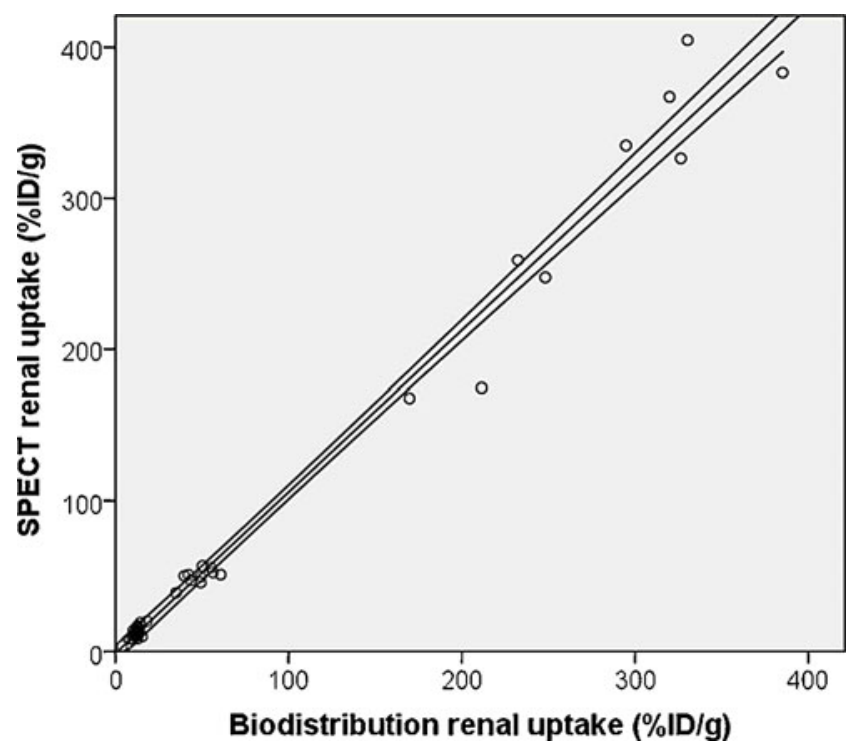

Fig. 5 Correlation between renal uptake measured ex vivo and uptake measured by SPECT. The data are from individual mice that were studied ex vivo after the final SPECT scan $\left({ }^{111}\right.$ In-minigastrin and ${ }^{111}$ In-exendin). Solid lines linear-fitted trend line with $95 \%$ confidence interval 
expression of Cre recombinase. Leheste et al. initially reported that approximately $10 \%$ of the proximal tubular cells of these mice express normal levels of megalin [12], and Motoyoshi et al. reported residual megalin expression in $35-50 \%$ of proximal tubular cells [23]. Immunohistochemical staining of kidney sections in the present study confirmed residual megalin expression and considerable variation between individual mice. In addition to residual expression of megalin, part of the residual uptake may also be explained by the involvement of other uptake mechanisms in the reabsorption of these peptides, such as fluid phase endocytosis [24] or other receptors. Proximal tubular expression of ligand-specific receptors for somatostatin, glucagon-like peptide-1 and cholecystokinin 2 has been described [25-27]. Cubilin, another multiligand receptor, is dependent on other transmembrane proteins such as megalin and amnionless for its internalization [28, 29]. In megalin-deficient mice, the internalization of cubilin may therefore also be reduced.

The data obtained in the current study with ${ }^{111}$ In-exendin were paradoxical: significantly reduced renal uptake in megalin-deficient mice was measured when the animals received an imaging dose of $2 \mathrm{nmol}$, but no significant difference between the two groups was found at a biodistribution dose of 5 pmol ${ }^{111}$ In-exendin. This paradox may very well be caused by the residual megalin expression in the megalin-deficient mice. The residual megalin receptors may still be able to internalize much of the 5 pmol dose, while they are saturated by the 2 nmol dose. Even though proximal tubular endocytosis is regarded as a low-specificity, high-capacity pathway, it can be blocked competitively by excesses of ligands [30, 31]. The difference between ${ }^{111}$ In-exendin and the other peptides in this respect might be explained by a relatively high affinity of ${ }^{111}$ In-exendin for megalin and/or associated receptors such as cubilin. This may also account for the very high baseline renal uptake of this peptide $(225-371 \% \mathrm{ID} / \mathrm{g})$ and suggests that megalin is indeed involved in the renal reabsorption of ${ }^{111}$ In-exendin.

The renal uptake of the radiolabelled peptides at $3 \mathrm{~h}$ after injection was similar in male and female mice. However, at $24 \mathrm{~h}$ after injection the uptake of ${ }^{111}$ In-octreotide and ${ }^{111}$ In-octreotate was significantly lower in male mice, which has been reported previously [13]. This suggests that the proximal tubular processing and retention of ${ }^{111}$ In-labelled somatostatin analogues differ between male and female mice, leading to more rapid washout of radioactivity in males. However, the ratios of uptake between megalin-deficient and wildtype mice were comparable in both genders at both timepoints, which suggests that the role of megalin in the reabsorption of radiopeptides is independent of gender influences.
Reduced proximal tubular reabsorption of radiolabelled peptides would be expected to cause increased excretion of the radiolabelled peptides in the urine without affecting plasma clearance, since glomerular filtration is not affected and reabsorbed radiolabelled peptides are not returned to the bloodstream. This was confirmed by our observation that the radioactivity concentrations of these radiolabelled peptides in the blood and in most organs other than the kidneys did not differ between megalin-deficient and wildtype mice. The one exception, lower uptake of ${ }^{111} \mathrm{In}$ exendin in the lungs of megalin-deficient mice, was only observed at the high peptide dose of $2 \mathrm{nmol}$. At the lower dose of 5 pmol, no difference between megalin-deficient and wild-type animals was observed, and lung uptake was approximately 5 -fold to 20 -fold higher than in the 2 -nmol groups. The lower uptake at the higher peptide dose was most likely due to saturation of specific lung uptake, which has also been described recently by Brom et al. [19]. The lower lung uptake in the megalin-deficient mice in this group may indicate involvement of megalin in the pulmonary uptake of this peptide. Megalin is expressed in the lungs [32], and this high-capacity receptor may contribute significantly to peptide uptake at higher concentrations, when specific glucagon-like peptide-1 receptor mediated uptake (high affinity but lower capacity) is saturated. Although the megalin ${ }^{\text {lox/lox; }}$ apoE ${ }^{\mathrm{Cre}}$ mice are described as kidney-specific megalin-deficient mice [12], apoE is also expressed in the lungs [33], which may cause reduced expression of megalin in the lungs of these animals. Possible lower expression of megalin in the lungs is unlikely to have affected the renal uptake of the studied peptides, as their concentrations in blood and other organs did not differ significantly between the megalin-deficient and wild-type mice.

In this study the renal uptake measured ex vivo and on SPECT images correlated very well, which confirms the previously reported accuracy of the small-animal SPECT system [34]. SPECT enables serial measurements in vivo and possibly the reuse of animals in multiple experiments. However, SPECT remains much less sensitive than ex vivo organ measurement, which means that only organs with a considerable uptake can reliably be imaged and relatively high radiation doses have to be administered. This can lead to complications: in the present study, mice that received a relatively high kidney radiation dose from ${ }^{111}$ In-exendin developed long-term kidney damage, which has been described and analysed in detail elsewhere [22]. In addition, high activity doses require administration of a relatively high peptide dose, which can influence a peptide's pharmacokinetics and biodistribution [19, 35].

Our results indicate that megalin plays an important role in the renal reabsorption of these diverse ${ }^{111} \mathrm{In}$ - 
labelled peptides. The variety of radiolabelled peptides and other ligands that are taken up via megalin suggests that it may also be involved in the renal reabsorption of other radiolabelled peptides. The knowledge that megalin is involved in the renal uptake of these radiolabelled peptides may help in the development of new strategies for the reduction of PRRT-induced nephrotoxicity. For example, the reduction in renal uptake of radiolabelled peptides by coadministration of compounds such as succinylated gelatin and albumin fragments [21, 36-38], is probably due to their competitive binding to megalin. Lysine, a positively charged amino acid, is used to reduce nephrotoxicity of clinical somatostatin analogue PRRT [10]. However, Gotthardt et al. have shown that lysine does not reduce the renal uptake of negatively charged minigastrin analogues, whereas negatively charged polyglutamic acids do reduce uptake of ${ }^{111}$ In-minigastrin, but not of the positively charged ${ }^{111}$ In-octreotide [9]. These observations suggest that different mechanisms are involved in the uptake of these radiolabelled peptides and seems to contradict our present findings that megalin is involved in the renal uptake of both peptides. However, megalin contains four large binding domains [6], and lysine and polyglutamic acid may bind selectively to distinct regions of these domains, thereby only interfering with the binding of specific radiolabelled peptides. The peptide mixtures in succinylated gelatin and albumin fragments are more likely to block several of megalin's binding regions, thereby interfering with the binding and uptake of several different radiolabelled peptides.

In conclusion, the multiligand receptor megalin plays an important role in the renal reabsorption of ${ }^{111}$ In-labelled octreotide, octreotate, minigastrin, exendin and neurotensin. This knowledge may be used in the development of new methods to reduce the renal retention of these peptides, thus reducing the risk of nephrotoxicity and improving the safety and effectiveness of PRRT.

\begin{abstract}
Acknowledgments We would like to express our thanks to Thomas E. Willnow and his group for kindly providing the megalin-deficient mice. Furthermore, we would like to thank Saskia Berndsen, Bianca Lemmers-van de Weem, Kitty Lemmens-Hermans, Erik de Blois, Jan de Swart, Suzanne Reneman, Cathelijne Frielink, Janneke Molkenboer-Kuenen, Lieke Joosten, Gabie de Jong, Gerben Franssen, Rafke Schoffelen and René te Morsche for their invaluable help with the animal experiments.
\end{abstract}

\section{Conflicts of interest None.}

Open Access This article is distributed under the terms of the Creative Commons Attribution Noncommercial License which permits any noncommercial use, distribution, and reproduction in any medium, provided the original author(s) and source are credited.

\section{Reference}

1. Christensen EI, Gburek J. Protein reabsorption in renal proximal tubule-function and dysfunction in kidney pathophysiology. Pediatr Nephrol. 2004;19:714-21.

2. Behr TM, Goldenberg DM, Becker W. Reducing the renal uptake of radiolabeled antibody fragments and peptides for diagnosis and therapy: present status, future prospects and limitations. Eur J Nucl Med. 1998;25:201-12.

3. Otte A, Herrmann R, Heppeler A, et al. Yttrium-90 DOTATOC: first clinical results. Eur J Nucl Med. 1999;26:1439-47.

4. Valkema R, Pauwels SA, Kvols LK, et al. Long-term follow-up of renal function after peptide receptor radiation therapy with $(90) \mathrm{Y}$ $\operatorname{DOTA}(0), \operatorname{Tyr}(3)$-octreotide and (177)Lu-DOTA(0), Tyr(3)octreotate. J Nucl Med. 2005;46 Suppl 1:83S-91S.

5. Christensen EI, Birn H. Megalin and cubilin: multifunctional endocytic receptors. Nat Rev Mol Cell Biol. 2002;3:256-66.

6. Orlando RA, Exner M, Czekay RP, et al. Identification of the second cluster of ligand-binding repeats in megalin as a site for receptorligand interactions. Proc Natl Acad Sci U S A. 1997;94:2368-73.

7. De Jong M, Barone R, Krenning E, et al. Megalin is essential for renal proximal tubule reabsorption of (111)In-DTPA-octreotide. J Nucl Med. 2005;46:1696-700.

8. Behr TM, Behe M, Angerstein C, et al. Cholecystokinin-B/gastrin receptor binding peptides: preclinical development and evaluation of their diagnostic and therapeutic potential. Clin Cancer Res. $1999 ; 5: 3124 \mathrm{~s}-38 \mathrm{~s}$.

9. Gotthardt M, Van Eerd-Vismale J, Oyen WJ, et al. Indication for different mechanisms of kidney uptake of radiolabeled peptides. J Nucl Med. 2007;48:596-601.

10. Rolleman EJ, Valkema R, De Jong M, Kooij PP, Krenning EP. Safe and effective inhibition of renal uptake of radiolabelled octreotide by a combination of lysine and arginine. Eur J Nucl Med Mol Imaging. 2003;30:9-15.

11. Rolleman EJ, Melis M, Valkema R, Boerman OC, Krenning EP, De Jong M. Kidney protection during peptide receptor radionuclide therapy with somatostatin analogues. Eur J Nucl Med Mol Imaging. 2010;37:1018-31.

12. Leheste JR, Melsen F, Wellner M, et al. Hypocalcemia and osteopathy in mice with kidney-specific megalin gene defect. FASEB J. 2003;17:247-9.

13. Melis M, Krenning EP, Bernard BF, De Visser M, Rolleman E, De Jong M. Renal uptake and retention of radiolabeled somatostatin, bombesin, neurotensin, minigastrin and CCK analogues: species and gender differences. Nucl Med Biol. 2007;34:633-41.

14. Kos CH. Cre/loxP system for generating tissue-specific knockout mouse models. Nutr Rev. 2004;62:243-6.

15. $\mathrm{Wu}$ F. Conditional targeting in the kidney. Nephron Physiol. 2007;107:10-6.

16. Bakker WH, Albert R, Bruns C, et al. [111In-DTPA-D-Phe1]octreotide, a potential radiopharmaceutical for imaging of somatostatin receptor-positive tumors: synthesis, radiolabeling and in vitro validation. Life Sci. 1991;49:1583-91.

17. De Jong M, Breeman WA, Bakker WH, et al. Comparison of (111)In-labeled somatostatin analogues for tumor scintigraphy and radionuclide therapy. Cancer Res. 1998;58:437-41.

18. De Visser M, Janssen PJ, Srinivasan A, et al. Stabilised 111Inlabelled DTPA- and DOTA-conjugated neurotensin analogues for imaging and therapy of exocrine pancreatic cancer. Eur J Nucl Med Mol Imaging. 2003;30:1134-9.

19. Brom M, Oyen WJ, Joosten L, Gotthardt M, Boerman OC. (68) Ga-labelled exendin-3, a new agent for the detection of insulinomas with PET. Eur J Nucl Med Mol Imaging. 2010;37:1345-55.

20. Behe M, Becker W, Gotthardt M, Angerstein C, Behr TM. Improved kinetic stability of DTPA-dGlu as compared with 
conventional monofunctional DTPA in chelating indium and yttrium: preclinical and initial clinical evaluation of radiometal labelled minigastrin derivatives. Eur J Nucl Med Mol Imaging. 2003;30:1140-6.

21. Vegt E, Eek A, Oyen WJ, De Jong M, Gotthardt M, Boerman OC. Albumin-derived peptides efficiently reduce renal uptake of radiolabelled peptides. Eur J Nucl Med Mol Imaging. 2010;37:226-34.

22. Melis M, Vegt E, Konijnenberg MW, et al. Nephrotoxicity in mice after repeated imaging using $111 \mathrm{In}$-labeled peptides. J Nucl Med. 2010;51:973-7.

23. Motoyoshi Y, Matsusaka T, Saito A, et al. Megalin contributes to the early injury of proximal tubule cells during nonselective proteinuria. Kidney Int. 2008;74:1262-9.

24. Barone R, Van der Smissen P, Devuyst O, et al. Endocytosis of the somatostatin analogue, octreotide, by the proximal tubule-derived opossum kidney (OK) cell line. Kidney Int. 2005;67:969-76.

25. Bates CM, Kegg H, Petrevski C, Grady S. Expression of somatostatin receptors 3,4 , and 5 in mouse kidney proximal tubules. Kidney Int. 2003;63:53-63.

26. Schlatter P, Beglinger C, Drewe J, Gutmann H. Glucagon-like peptide 1 receptor expression in primary porcine proximal tubular cells. Regul Pept. 2007;141:120-8.

27. de Weerth A, Jonas L, Schade R, et al. Gastrin/cholecystokinin type B receptors in the kidney: molecular, pharmacological, functional characterization, and localization. Eur J Clin Invest. 1998;28:592-601.

28. Coudroy G, Gburek J, Kozyraki R, et al. Contribution of cubilin and amnionless to processing and membrane targeting of cubilinamnionless complex. J Am Soc Nephrol. 2005;16:2330-7.

29. Hammad SM, Barth JL, Knaak C, Argraves WS. Megalin acts in concert with cubilin to mediate endocytosis of high density lipoproteins. J Biol Chem. 2000;275:12003-8.
30. ten Dam MAGJ, Branten AJW, Klasen IS, Wetzels JFM. The gelatin-derived plasma substitute Gelofusine causes lowmolecular-weight proteinuria by decreasing tubular protein reabsorption. J Crit Care. 2001;16:115-20.

31. Mogensen CE, Sølling. Studies on renal tubular protein reabsorption: partial and near complete inhibition by certain amino acids. Scand J Clin Lab Invest. 1977;37:477-86.

32. Zheng G, Bachinsky DR, Stamenkovic I, et al. Organ distribution in rats of two members of the low-density lipoprotein receptor gene family, gp330 and LRP/alpha 2MR, and the receptor-associated protein (RAP). J Histochem Cytochem. 1994;42:531-42.

33. Srivastava RA, Bhasin N, Srivastava N. Apolipoprotein E gene expression in various tissues of mouse and regulation by estrogen. Biochem Mol Biol Int. 1996;38:91-101.

34. Forrer F, Valkema R, Bernard B, et al. In vivo radionuclide uptake quantification using a multi-pinhole SPECT system to predict renal function in small animals. Eur J Nucl Med Mol Imaging. 2006;33:1214-7.

35. De Jong M, Breeman WA, Bernard BF, et al. Tumour uptake of the radiolabelled somatostatin analogue [DOTA0, TYR3]octreotide is dependent on the peptide amount. Eur J Nucl Med. 1999;26:693-8.

36. Van Eerd JE, Vegt E, Wetzels JF, et al. Gelatin-based plasma expander effectively reduces renal uptake of $111 \mathrm{In}$-octreotide in mice and rats. J Nucl Med. 2006;47:528-33.

37. Vegt E, Wetzels JF, Russel FG, et al. Renal uptake of radiolabeled octreotide in human subjects is efficiently inhibited by succinylated gelatin. J Nucl Med. 2006;47:432-6.

38. Vegt E, Van Eerd JE, Eek A, et al. Reducing renal uptake of radiolabeled peptides using albumin fragments. J Nucl Med. 2008;49:1506-11. 